\title{
Huge Left Atrial Extension of Metastatic Lung Tumor via Pulmonary Vein: Report on the Third Case of Osteosarcoma
}

\author{
Cetin Celenk ${ }^{\mathrm{a}, \mathrm{c}}$, Muzaffer Elmali ${ }^{\mathrm{a}}$, A. Veysel Polat ${ }^{\mathrm{a}}$, Aysen Taslak Sengul $^{\mathrm{b}}$
}

\begin{abstract}
The antemortem diagnosis of cardiac metastases in osteogenic sarcoma has been documented in only 26 cases over the past 55 years, approximately. However, extension of metastatic lung tumors into the left atrium via pulmonary veins is very rare. Here, we report the third case of osteosar $\neg$ coma exhibiting such extension. A 25 -yearold woman with pulmonary metastasis from osteosarcoma presented with a huge mass in her left lung, extending to the left atrium through the left inferior pulmonary vein.
\end{abstract}

Keywords: Osteosarcoma; Lung metastasis; Left atrial tumor extension; Tumor invasion of pulmonary veins

\section{Introduction}

Lung cancer is one of the most common causes of metastatic cardiac tumours, but very few cases of intracardiac extension via the pulmonary vein have been seen [1-3]. Primary pulmonary malignancies with invasion of the pulmonary veins and left atrium (LA) occurred most frequently in non-small cell carcinoma of the lung [2].

Indeed, in our exam $\rightarrow$ ination of the literature, we noted only 26 heart ostesarcoma metastasis cases over the past 55 years. To our knowledge, the case presented here is the third citing intra-left atrial extension via the pulmonary vein by metastatic osteosarcoma.

Manuscript accepted for publication November 19, 2012

${ }^{a}$ Department of Radiology, Faculty of Medicine, Ondokuz Mayis University, Samsun, Turkey

${ }^{b}$ Department of Thoracic Surgery, Faculty of Medicine, Ondokuz Mayis University Samsun, Turkey

${ }^{\mathrm{c} C}$ Corresponding author: Cetin Celenk, Ondokuz Mayis University, Tip

Fakultesi, Radyoloji. 55139, Samsun, Turkey.

Email: ccelenk@hotmail.com

doi: http://dx.doi.org/10.4021/jmc605w

\section{Case Report}

Three years ago, a 25-year-old female patient was admitted to the orthopedic clinic for three months because of increased swelling and pain in her left knee.

Magnetic resonance imaging (MRI) revealed a large mass in her femur distal area at the left-knee, with no evidence of distant metastasis noted on positron emission tomography-computed tomography (PET/CT). Following open biopsy, she was diagnosed with osteosarcoma.

The patient performed a complete resection of the primary tumor after three courses of chemotherapy.

The following year, pulmonary metastases were identified on a follow-up chest CT scan. Two metastatic nodules were removed from the left lover pulmonary lobe. Two years after the surgery, a CT scan revealed multiple bilateral pulmonary calcific node metastases (the largest was $25 \times 47$ $\mathrm{mm}$ in diameter and located in the left lower lobe) (Fig. 1). Because these new pulmonary tumors were unresectable, systemic chemotherapy was performed. Three years after the surgery, a follow-up contrast chest CT scan revealed a mass of approximately $5 \times 10 \mathrm{~cm}$ in diameter extending into the left atrium through the pulmonary vein with amorphous calcifications and hypodense areas (Fig. 2). The physical examination revealed no remarkable findings, and the patient presented no further symptoms. Laboratory findings were all within normal ranges. Pulmonary function was normal, and trans $\neg$ thoracic echocardiography confirmed normal cardiac function.

The patient was referred to thoracic surgeons for potential surgical resection. At a multidisciplinary conference, we decided to recommend removal of the tumor to prevent massive tumor emboli and sudden cardiac dysfunction owing to intracardiac extension. However, because these new cardiac tumors were unresectable, systemic chemotherapy was performed.

\section{Discussion}

Metastases to the heart and pericardium are much more com- 


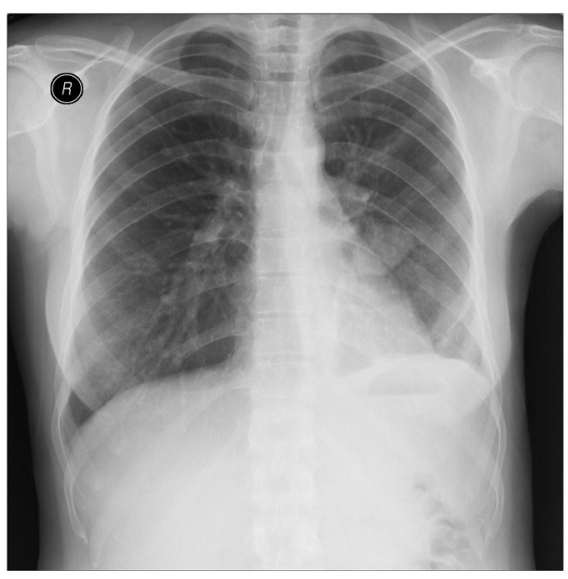

a
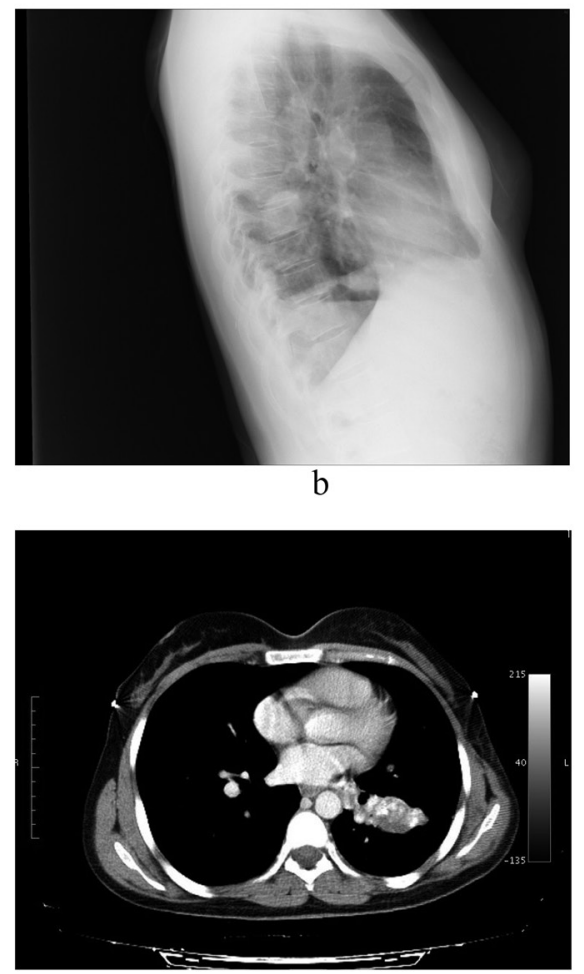

$\mathrm{C}$

Figure 1. (a) PA chest X-Ray, (b) Lateral chest X-Ray, (c) Axial chest computed tomography scan. Metastatic nodules are seen.

mon than primary cardiac tumors and are generally associated with a poor prognosis [1-4]. Such extension occurs most frequently in non-small cell carcinomas, but also has been reported in primary pulmonary sarcoma. Metastases to the heart occur with approximately $15 \%$ of all sarcomas $[2,3]$.

Secondary intracardiac neoplasms arise most frequently from renal cell carcinoma, bronchogenic carcinoma, Wilms' tumor, chondrosarcoma, and osteogenic sarcoma $[3,5]$.

In contrast to primary osteosarcomas of the heart, osteosarcoma metastases to the heart are often right-sided, suggesting intravascular and intracardiac seeding and/or spread. Documented cases of the tumor reaching the right heart via pulmonary venous extension are sparse [6].

The reported symptoms and signs in patients with metastatic osteogenic sarcoma of the heart include dyspnea, syncope, peripheral cyanosis and subcutaneous edema secondary to massive tumor invasion, and compression or obstruction of the venous system [5].

Chest radiography may show pulmonary metastases and/or bony structure metastases (radiographically visible) inside the heart, which is the most unique feature of osteogenic sarcoma involving the heart [5]. In our case, the initial symptoms of chest tightness and exertional dyspnea were considered nonspecific. There was tumor plop and cardiac murmur, the results of cardiac examination. There was bone formation in the intracardiac tumor in the chest X-ray.

Osteogenic sarcoma involving the heart is unique in that the metastases contain bone. In patients with osteogenic sarcoma, the calcific areas of increased opacity may be visible on chest radiographs but are better demonstrated on CT scans as high-attenuation lesions [5].

However, we found that left atrial extension of metastatic lung tumors through pulmonary veins is extremely rare; only 13 cases, including the patient, have been reported in the literature. These cases were chondrosarcoma $(n=5)$ [7-10], osteosarcom $(n=2)$ [11, 12], leiomyosarcoma [13], malignant fibrous histiocytoma [14], synovial sarcoma [15], Ewing sarcoma [16] and carcinoma of the cervix ( $\mathrm{n}=1$ each) [11]. To our knowledge, ours is the third reported case of osteosarcoma exhibiting such extension. Although carcinomas of the colon, breast, kidneys, and head and neck frequently metastasize to the lungs, only one case of cervical cancer has been reported to show this type of extension. Given that sarcomas tend to metastasize through the vasculature instead of the lymphatic system, sarcomas may exhibit invasion distinct from carcinoma.

In the present case, however, the patient had multiple unresectable metastases (lung). In addition, even though palliative resections are often performed in the oncology practice to ease certain tumor-related symptoms, this patient was 


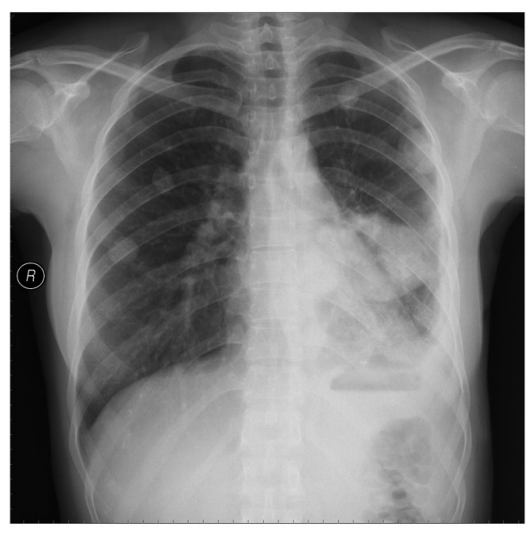

a

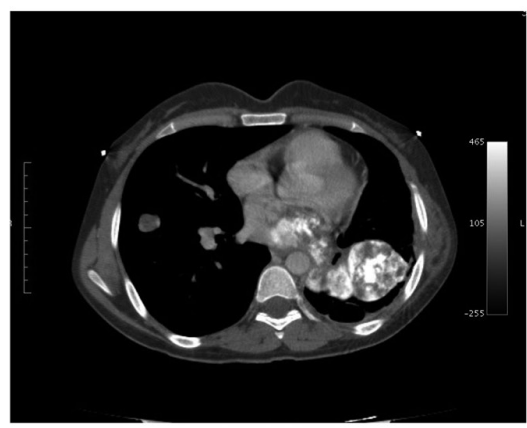

c

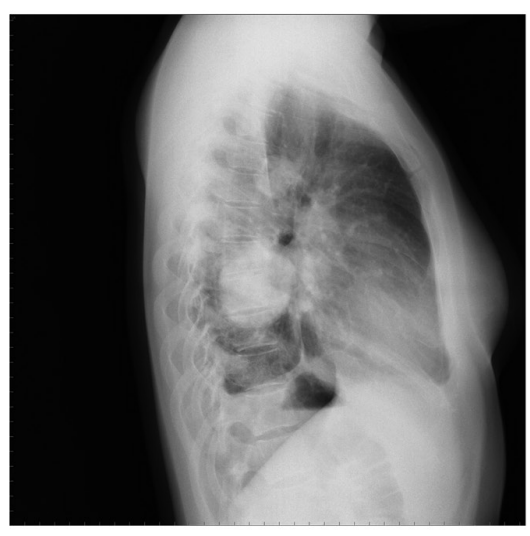

$\mathrm{b}$

Figure 2. (a) PA chest X-Ray, (b) Lateral Chest X-Ray, (c) Axial chest computed tomography scan. A mass can be seen moving toward the left atrium via the pulmonary vein.

asymptomatic. In our case, we considered that the growing tumor might induce sudden cardiac arrest owing to obstruction of cardiac inflow. In light of this possibility, we recommended prophylactic surgical resection of the tumor.

In summary, we experienced a case of metastatic lung tumors extending into the left atrium via the pulmonary vein. Metastatic tumors exhibiting this type of extension are extremely rare, and this particular case is the third known report of its occurrence with osteosarcoma. Given the severe complications that have been reported in patients with this type of extension, immediate prophylactic surgery should be considered.

\section{References}

1. Lin MT, Ku SC, Wu MZ, Yu CJ. Intracardiac extension of lung cancer via the pulmonary vein. Thorax. 2008;63(12):1122.

2. Roberts TE, Hasleton PS, Musgrove C, Swindell R, Lawson RA. Vascular invasion in non-small cell lung carcinoma. J Clin Pathol. 1992;45(7):591-593.

3. Lam KY, Dickens P, Chan AC. Tumors of the heart. A 20-year experience with a review of 12,485 consecutive autopsies. Arch Pathol Lab Med. 1993;117(10):1027-
1031.

4. Mukai K, Shinkai T, Tominaga K, Shimosato Y. The incidence of secondary tumors of the heart and pericardium: a 10-year study. Jpn J Clin Oncol. 1988;18(3):195201.

5. Seibert KA, Rettenmier CW, Waller BF, Battle WE, Levine AS, Roberts WC. Osteogenic sarcoma metastatic to the heart. Am J Med. 1982;73(1):136-141.

6. Burke AP, Virmani R. Osteosarcomas of the heart. Am J Surg Pathol. 1991;15(3):289-295.

7. Woodring JH, Bognar B, van Wyk CS. Metastatic chondrosarcoma to the lung with extension into the left atrium via invasion of the pulmonary veins: presentation as embolic cerebral infarction. Clin Imaging. 2002;26(5):338341.

8. Gardner MA, Bett JH, Stafford EG, Matar K. Pulmonary metastatic chondrosarcoma with intracardiac extension. Ann Thorac Surg. 1979;27(3):238-241.

9. MacLowry JD, Roberts WC. Metastatic choriocarcinoma of the lung. Invasion of pulmonary veins with extension into the left atrium and mitral orifice. Am J Cardiol. 1966;18(6):938-941.

10. Oizumi H, Tanaka R, Shimura H, Sasaki K, Koike H, Hattori N, Tanaka S. A case of cerebral embolism with metastatic chondrosarcoma in the left atrium. J Stroke 
Cerebrovasc Dis. 2011;20(1):79-81.

11. Gandhi AK, Pearson AC, Orsinelli DA. Tumor invasion of the pulmonary veins: a unique source of systemic embolism detected by transesophageal echocardiography. J Am Soc Echocardiogr. 1995;8(1):97-99.

12. Senbo J, Sasaki T, Hasegawa Y, Kato N, Kawamura K, Watanabe Y, Koyama N, et al. [Resection of metastatic pulmonary lesion of osteosarcoma extended into the left atrium and ventricle via the pulmonary vein]. Kyobu Geka. 1991;44(11):929-932.

13. Collins NJ, Barlow MA, Woodford PA, Hayes PC. Intracardiac extension of metastatic pulmonary leiomyosarcoma. Heart Lung Circ. 2005;14(2):121-122.
14. Ishibashi H, Akamatsu H, Egi K, Tanaka H, Sunamori $\mathrm{M}$. [A case of pulmonary metastasis of malignant fibrous histiocytoma with left atrial infiltration via the pulmonary vein]. Kyobu Geka. 2001;54(10):895-897.

15. Heslin MJ, Casper ES, Boland P, Gold JP, Burt ME. Preoperative identification and operative management of intraatrial extension of lung tumors. Ann Thorac Surg. 1998;65(2):544-546.

16. Funakoshi Y, Mukohara T, Kataoka T, Tomioka H, Chayahara N, Fujiwara Y, Kiyota N, et al. Left atrial extension of metastatic lung tumor via pulmonary vein: report on the first case of Ewing sarcoma. Rare Tumors. 2010;2(3):e53. 